\title{
DERMATITIS HERPETIFORMIS, THE CELIAC DISEASE OF THE SKIN!
}

\author{
Lorete Maria da Silva KOTZE
}

\section{INTRODUCTION}

Gluten-related diseases were recently classified into three groups according to their physiopathological mechanisms: autoimmunity (celiac disease, dermatitis herpetiformis, gluten ataxia), allergy (wheat allergy- respiratory, alimentary, contact urticary and WDEIA) and no-autoimmune no-allergic (gluten sensitivity) $)^{(30)}$.

Dermatitis herpetiformis (DH) is an autoimmune blistering cutaneous disease that appears as a consequence of gluten intolerance. There is evidence that $\mathrm{DH}$ should be considered as the specific phenotypic cutaneous expression of a gluten-sensitive enteropathy indistinguishable from celiac disease $(\mathrm{CD})^{(36)}$. Immunological studies demonstrated the presence of granular deposits of IgA along the dermal-epidermal junction ${ }^{(32)}$.

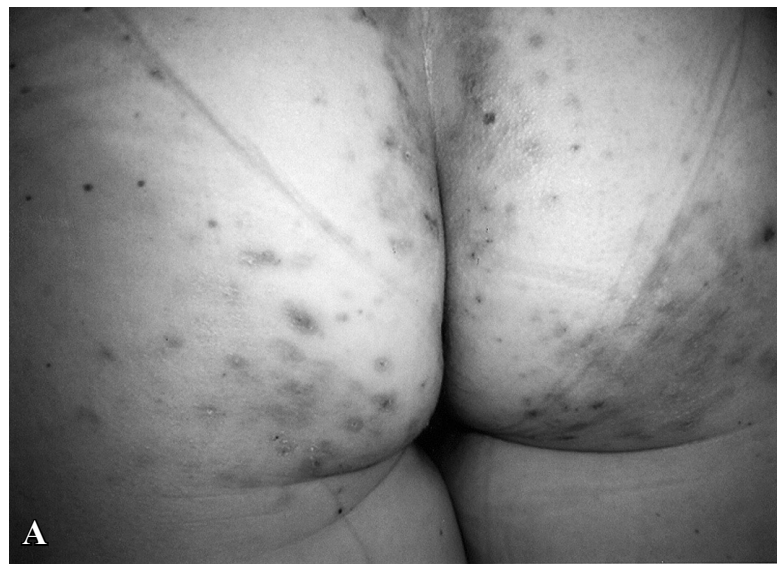

This disorder generally has a typical presentation (pruritic papulovesicular rash predominantly on extensor surfaces and on the buttocks) (Figure 1-A), but atypical presentations may occur (purpuric lesions in the palm of hands in children, and lesions in the oral and genital mucosa in adults ${ }^{(23)}$; or lesions in scalp, nuchal area, face and groin). Some celiac patients referred to changes in the skin (like thickness) related to the consumption of gluten, but without apparent lesions. It is important for the gastroenterologist to know about these facts since, in many cases, only a gluten-free diet (GFD) is not sufficient to reverse the lesions, and medication (such as dapsone) needs to be prescribed (Figure 1-B). It is crucial to diagnosis DH as early as possible because these patients are faced with reduction in the quality of life, mainly due to the need for lifelong gluten-free diet, change in eating habits and life style ${ }^{(18)}$.

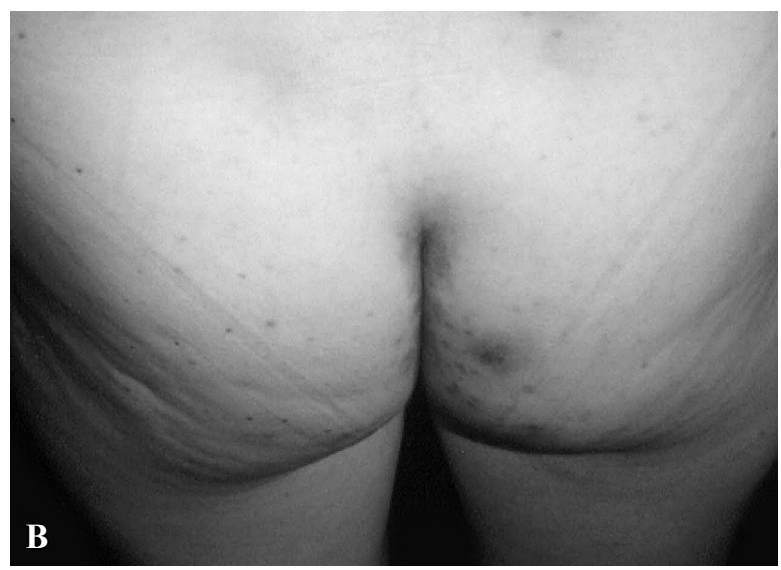

FIGURE 1. Dermatitis herpetiformis. A - Pruritic papulovesicular rash on the buttocks. B - Great improvement of the lesions after 30 days on gluten-free diet and orally dapsone. 


\section{HISTORY}

DH was described and named in 1884 by Dr. Louis Duhring, a dermatologist at the University of Pennsylvania ${ }^{(8)}$. The association of DH and enteropathy was described in 1966 by Dr. Janet Marks et al. ${ }^{(22)}$. In 1969 Van der Meer ${ }^{(32)}$ in Holland described the presence of granular immunoglobulin (Ig) A in the dermal papillary tips of skin from patients with $\mathrm{DH}$, currently recognized as the hallmark of the disease. Dr. Lionel Fry et al. (England), Dr. Timo Reunala et al. (Finland), Drs. Mobacken and Kastrups et al. (Sweden), Dr. Steven Katz and Dr. Russel Hall (USA) published important papers about the affection (apud ZONE 2005) ${ }^{(36)}$. Dr. Kumar, in 2001, at the University of Buffalo is credited with the discovery of the endomysial antibody in patients with $\mathrm{DH}^{(20)}$. Dr. Zone has evaluated more than 800 patients since $1970^{(36,37)}$.

\section{EPIDEMIOLOGY}

The prevalence of $\mathrm{DH}$ has been reported to be $1.2 \mathrm{per}$ 100,000 population in Great Britain (1971), 39.2 per 100,000 population in central Sweden (1984) and 11.2 per 100.000 population in Utah - USA (1992) (2). The incidence of DH in the last report was 0.98 per 100.000 population $^{(36)}$.

DH could appear in any age with the onset of symptoms in the third or fourth decade, being an exception in children under 3 years of age. Unlike CD, DH is more frequent in males $\sim 1.4: 1$. About $5 \%$ of the patients with $\mathrm{CD}$ will present $\mathrm{DH}$ in their lifetime ${ }^{(19,23)}$. The patients may present $\mathrm{DH}$ before or after the diagnosis of $\mathrm{CD}^{(19)}$.

In Brazil, a unique report on this subject is credited to Kotze (the author of this revision), referring to DH in $11.5 \%$ of the 157 studied patients with $\mathrm{CD}^{(16)}$. High prevalence of DH in males was also established by the same author ${ }^{(18)}$.

\section{DIAGNOSIS}

The diagnosis of DH requires a complex approach: clinical, histological and immunological, considering atypical variants of the disease frequently described in the literature ${ }^{(3)}$.

\section{Digestive manifestations}

Although all the patients with DH present gluten sensitivity, a great majority are asymptomatic from the digestive point of view ${ }^{(13)}$. Alonso-Llamazares et al., reviewing the Mayo Clinic experience, referred to $13 \%$ of digestive complaints in 300 patients with DH (diarrhea, abdominal pain or failure to thrive in children $)^{(1)}$. The intestinal biopsy performed in patients with $\mathrm{DH}$ could reveal signs of gluten sensitivity in $60 \%$ to $75 \%$, ranging from normal - appearing epithelium to a flat mucosa (Marsh I to III) ${ }^{(1)}$.

\section{Cutaneous manifestations}

The most commonly involved sites in $\mathrm{DH}$ are those of symmetrical distribution on the extensor surfaces of the elbows $(90 \%)$, knees $(30 \%)$, shoulders, buttocks, sacral region, and face. The polymorphic lesions may be diffused or grouped: erythema, urticarial plaques, papules, herpetiform vesiculae and blisters (Figure 1-A). Erosions, excoriations and hyperpigmentation follow. Itching of variable intensity, scratching and burning sensation could predict the appearance of lesions ${ }^{(23)}$. Many patients referred to a burning sensation even before the onset of skin lesions ${ }^{(3)}$.

From the pathogenic point of view, CD4+ T cells with cytokine expression pattern belonging to the Th2 phenotype has been documented in recent DH lesions along with perilesional $\operatorname{skin}^{(9)}$.

Figure 2 shows the recommended tests confirming DH.

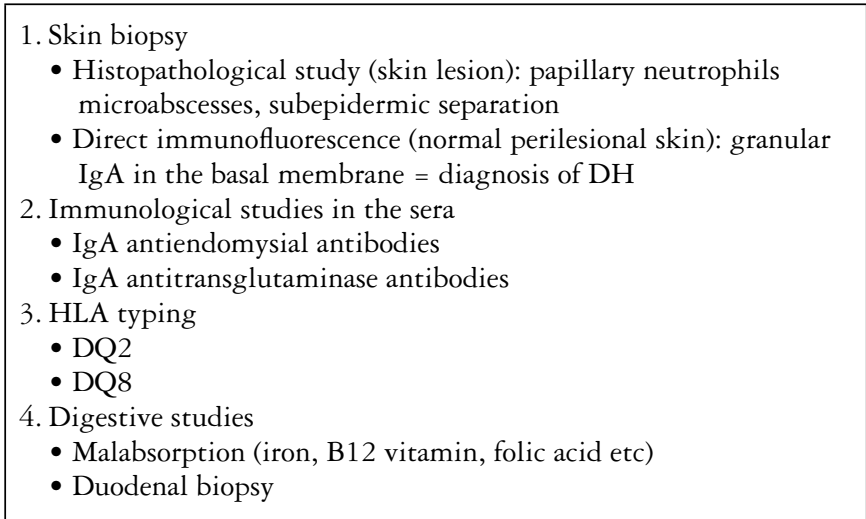

FIGURE 2. Tests for the diagnosis of dermatitis herpetiformis adapted from Herrero-Gonzales ${ }^{(13)}$

\section{Histopathology}

The classic features of DH under light microscopy are the subepidermal cleft with neutrophils (considered mainly responsible for the dermal-epidermal separation) and a few eosinophils at the tips of dermal papillae, often with a perivascular mixed inflammatory infiltrate. But in patients with pruritic and excoriated lesions, histological findings could not confirm DH, maybe because of an error in the site of the biopsy ${ }^{(36,37)}$.

Direct immunofluorescence of uninvolved skin collected in the perilesional site is considered the gold standard for the diagnosis of $\mathrm{DH}^{(4,5,34)}$. The choice of normal appearing perilesional skin for biopsy is fundamental as patients showed greater IgA deposition at this site than in non lesional or lesional skin, as demonstrated by Zone et al. ${ }^{(37)}$.

There are two different patterns: granular deposits in the dermal papillae or granular deposits along the basement membrane (a combination of both could occur). These deposits are polyclonal, mainly composed of $\operatorname{IgA} 1^{(33)}$. Warren and Cockerell ${ }^{(34)}$ reported the characterization of a subgroup of patients with $\mathrm{DH}$ with non-classical histological features.

\section{Immunological determinations in the sera}

DH patients have no circulating autoantibodies binding to the cutaneous basement membrane components or to other adherent structures of the skin, even considering that epidermal transglutaminase (TGase 3 ) is the autoantigen of $\mathrm{DH}^{(15,26)}$. 
As DH presents variable degrees of enteropathy, the correlation with serological tests is difficult ${ }^{(33)}$. The tests indicated are IgA antiendomysial (detected by indirect immunofluorescence) ${ }^{(33)}$ and/or anti-tissue transglutaminase (detected by ELISA) $)^{(7)}$. Both correlate with small bowel damage and adherence to gluten-free diet. Sugai et al. suggested that deamidated synthetic gliadin-derived peptide (a-GDP) was more sensitive ${ }^{(29)}$. Volta et al. reported the correlation between IgA antiendomysial antibodies and subtotal villous atrophy in $\mathrm{DH}^{(33)}$.

\section{HLA typing}

The prevalence of HLA DQ2 and DQ8 is the same as in $\mathrm{CD}$, supporting the concept that $\mathrm{DH}$ is a skin manifestation of CD. About $90 \%$ of the patients with DH express HLA DQ2 ( $20 \%$ of controls); the others, DQ8. Patients without the two predisposing HLA types are extremely rare $^{(6)}$.

$\mathrm{DH}$, like $\mathrm{CD}$, is familial, since $10 \%-15 \%$ of the first-degree relatives of patients with $\mathrm{DH}$ present $\mathrm{CD}$ or $\mathrm{DH}$. In the experience of Kotze et al., among fourteen cases of $\mathrm{DH}$, one male patient referred to a sister with DH $(7.15 \%)^{(18)}$.

\section{Digestive approaches}

Tests studying intestinal malabsorption are recommended in some patients for detection of deficiencies (iron, vitamin B12, folic acid, calcium etc) ${ }^{(11)}$.

\section{Small bowel biopsy}

Small bowel biopsy is considered unnecessary for DH patients by some authors ${ }^{(4)}$. It is not the opinion of the author of this study as DH can present lymphoma with time and it is important to compare the findings in intestinal biopsies at the diagnosis stage and when a neoplasia is suspected ${ }^{(16)}$. The adherence to a GFD could be monitored by serological tests and skin lesions observations, if the skin lesions recur within few days of gluten ingestion ${ }^{(4)}$.

\section{Associated autoimmune diseases}

$\mathrm{DH}$, like $\mathrm{CD}$, can be associated with other autoimmune diseases (Hashimoto thyroiditis, insulin-dependent diabetes mellitus, pernicious anemia, nephropathies, liver diseases, multiple sclerosis, Sjogren's syndrome, lupus erythematous, rheumatoid arthritis, vitiligo, psoriasis) or with Down syndrome). It is important to screen for these disorders mainly if there is a complaint or familial report ${ }^{(16,18)}$.

\section{Complications}

Like in CD, patients with $\mathrm{DH}$ are at risk of contracting lymphoma (10.3), 5.4 in men. Hervonen et al. reported 1.0\% among 1104 cases in Finland ${ }^{(14)}$. Although the lymphoma most associated with CD is EATL, in DH, diffused large B-cell lymphoma is observed ${ }^{(16)}$. This disorder can occur both inside and outside the gastrointestinal tract as a nodal or extranodal disease.

Whether a GFD protects against the development of lymphoma in CD is controversial. In DH patients, the adherence to a GFD could be not strict and most of them needed dapsone for longer periods. These facts could increase the risk of neoplasias. The occurrence of lymphoma in the first-degree relatives did not seem to increase when compared with that of the general population ${ }^{(14)}$.

\section{Differential diagnosis}

The differential diagnosis is concerned with scabies, atopic dermatitis, contact eczema, impetigo and other autoimmune bullous disorders like lineal IgA dermatosis and penfigo. The histopathological findings are fundamental as are the direct immunofluorescence findings ${ }^{(5)}$.

\section{Treatment}

The treatment of DH involves lifelong GFD for all the patients (gluten from wheat, barley, rye, and oats because of contamination $)^{(4)}$. The treatment is efficient for the disappearance of cutaneous and digestive manifestations, resulting in general well-being, reduction in or elimination of medication, resolution of enteropathy and the correlated malabsorption of essential nutrients and prevention of lymphomas ${ }^{(14)}$. More studies are required to determine whether a long-term GFD will decrease the concurrent autoimmune conditions in patients with $\mathrm{DH}^{(16)}$.

GFD alleviates digestive symptoms much more rapidly than the rash: it takes an average of 2 years of GFD for complete elimination of cutaneous lesions, which invariably recurs within 12 weeks after the reintroduction of gluten ${ }^{(12)}$. IgA antibodies may disappear from the dermal-epidermal junction after many years of a strict GFD, although on reintroduction of gluten, $\operatorname{IgA}$ deposits reappear in the skin and are also present when the rash recurs ${ }^{(31)}$. But only $10 \%$ $20 \%$ of the patients develop immunological tolerance and are capable of having a normal diet after years of GFD.

Despite the benefits of a GFD, it is not easy for the DH patients to maintain strict adherence to it: it is time-consuming and socially restricting. Consultation with a dietician and participation in support groups are strongly recommended ${ }^{(16,25)}$.

Although GFD is considered the only effective treatment for individuals with $\mathrm{DH}$ and $\mathrm{CD}$, a better understanding of the complexity of the genetic/environmental interactions responsible for both diseases opened up possibilities to a novel therapy ${ }^{(10)}$.

\section{Dapsone}

Dapsone (diaminodiphenylsulfone) is a valid therapeutic option for DH during the initial 1 or 2 years until GFD is effective $^{(12)}$. The dosages of $1 \mathrm{mg} / \mathrm{kg} /$ day can control itching and blister development (Figure 1-B). It is prudent to start the treatment with low dosage like $50 \mathrm{mg}$ per day, increasing it to $200 \mathrm{mg}$ according to the necessity and tolerance of the patient. Before starting the use of this drug, determination of the levels of glucose-6-phosphate-desydrogenase and renal and hepatic profile are indicated ${ }^{(13)}$. During treatment, regular controls include clinical evaluation and laboratory tests according to the response to treatment $t^{(25)}$. The contraindications of the use of dapsone are allergy to sulfonamides, 
paraminobenzoic acid, acute porfiria, anemia or severe cardiopulmonary disorder and deficit of glucose-6-fostatodeshidrogenase. Dapsone is not indicated in pregnancy or lactation. It presents interactions with probenecid and trimetoprim. The toxicity depends on the dosage for hemolisis and metahemoglobinemia ${ }^{(28)}$.

Because of severe adverse effects, patients need to be monitored specially for renal and liver functions. The adverse reactions to dapsone are classified as toxic (metahemoglobinemia, hemolytic anemia) or idiosyncratic (dapsone hypersensitivity syndrome: general malaise, exanthematous eruption, photosensitivity, neurological effects, nephropathy, hypothyroidism, gastrointestinal effects). In general, $5 \%$ of the patients develop problems $2-6$ weeks after the beginning of treatment ${ }^{(28)}$.

Dapsone suppresses inflammation in the skin, but has no influence on intestinal abnormality. So, many patients with $\mathrm{DH}$ choose to take dapsone chronically and not restrict gluten intake, despite knowing that gluten is the causative agent of their eruption ${ }^{(28)}$.

Dapsone is clinically useful in diseases containing neutrophilic infiltrates, inhibiting neutrophil myeloperoxidase, decreasing the damage from the neutrophil respiratory burst pathway mediated by this enzyme. The anti-inflammatory properties of topical dapsone benefit patients with acne and could also hinder the immunologic cascade and accompanying inflammatory process that occurs in DH. So, Handler et al. using dapsone $5 \%$ gel, reported an adjuvant effect in the treatment of a teenage patient with low doses of oral dapsone. As facial disease may be refractory to oral dapsone therapy, it is a new option for treatment ${ }^{(12)}$.

The oral association of vitamin E (800 U/day) or cimetidine (1.2 to $1.6 \mathrm{~g} / \mathrm{day})$ could be recommended to minimize the risk of hemolytic anemia and metahemoglobinemia ${ }^{(24)}$. Taking the dosage divided into two occasions could reduce the blood concentration and the toxicity of the medication.

\section{Sulfasalazine and sulphamethoxypyridazine}

These drugs could be an effective alternative for the treatment of DH when the use of dapsone fails or presents side effects. The suggested dosages are 1-2 g/day for sulfasalazine and $0.25-1.5 \mathrm{~g} /$ day for sulphamethoxypyridazine. As these mentioned medications also induce adverse effects, controls are necessary monthly or 6 monthly. Enteric-coated forms of the drugs could be prescribed ${ }^{(35)}$.

\section{Other drugs}

Topic corticosteroids (clobetasol propionate) could be of relative utility, but systemic glucocorticosteroids are not indicated to treat DH. Although with not high efficacy, third-generation antihistamines with specific activity on eosinophilic granulocytes may be used to control the pruritus and itching ${ }^{(4)}$. Immunosuppressants such as azathioprine, mycophenolate mofetil or methotrexate could be indicated in cases of non-response to a GFD plus dapsone. The author has a patient who used azathioprine for 2 years and then could be free of lesions only with a GFD (personal communication). Rituximab could be another possibility of treatment ${ }^{(27)}$. But $\mathrm{DH}$, as $\mathrm{CD}$, can appear in patients using infliximab for ankylosing spondylitis or inflammatory bowel disease, probably because TNF inhibitors could alter immunity and this would promote an inflammatory autoimmune response in the skin of predisposed individuals ${ }^{(21)}$.

\section{Follow-up}

Patients with DH should be evaluated at regular intervals (6 months after diagnosis and then yearly ) by a physician and a dietician. The purpose includes compliance with GFD, reinforcing the importance of the diet, and to detect early signs of malabsorption and/or associated diseases. Monitoring the diet with serological tets (IgA EmA or IgA anti-tTG) is sensitive for major but not for minor transient dietary indiscretions ${ }^{(17)}$.

\section{CONCLUSIONS}

Physicians treating patients with $\mathrm{CD}$ should be alert for skins manifestations of gluten sensitivity, not always characteristic of $\mathrm{DH}$. On the other hand, dermatologists may be aware of digestive implications of DH per se and the systemic actions of dapsone, including liver function alterations. For men with $\mathrm{DH}$, periodic control is fundamental as lymphoma needs to be diagnosed as soon as possible to give opportunity of treatment. 


\section{REFERENCES}

1. Alonso-Llamazares J, Gibson LE, Rogers RS 3rd. Clinical, pathologic, and immunopathologic features of dermatitis herpetiformis: review of the Mayo Clinic experience. Int J Dermatol. 2007;46:910-9.

2. Bolontin D, Petronic-Rosic V. Dermatitis herpetiformis: part I. Epidemiology, pathogenesis, and clinical presentation. J Am Acad Dermatol. 2011;64:1017-24.

3. Bonciolini V, Bonciani D, Verdelli A, D'Errico A, Antiga E, Fabbri P, Caproni M. Newly described clinical and immunopathological feature of dermatitis herpetiformis. Clin Develop Immunol. 2012. doi: 10.1155/2012/967974.

4. Caproni M, Antiga E, Melani L, Fabbri P. The Italian Group for Cutaneous Immunopathology. Guidelines for the diagnosis and treatment of dermatitis herpetiformis. J Eur Acad Dermatol Venereol. 2009; 23:633-8.

5. Chang D. The need for direct immunofluorescence in the diagnosis of IgA bullous dermatosis. J Bras Patol Med Lab. 2012;48:55-7.

6. Collin P, Reunala T. Recognition and manegment of cutaneous manifestations of celiac disese: a guide for dermatologists. Am J Clin Dermatol. 2003; 4:13-20.

7. Dieterich W, Laag E, Bruckner-Tuderman L, Reunala T, Karpati S, Zagoni T, Riecken EO, Schuppan D. Antibodies to tissue transglutaminase as serologic markers in patients with dermatitis herpetiformis. J Invest Dermatol. 1999;113:133-36.

8. Duhring L. Dermatitis herpetiformis. JAMA. 1884;3:225-8.

9. Fabbri P, Calabro AS, Hashimoto T, Fasano A, Caproni M. Novel advances in dermatitis herpetiformis. Clin Develoment Immunol. 2012.

10. Fasano A. Novel therapeutic/integrative approaches for celiac disease and dermatitis herpetiformis. Clin Develop Immunol. 2012. doi: 10.1155/2012/959061

11. Fry L, Keir P, McMinn RM, Cowan JD, Hoffbrand AV. Small intestinal structure and function and haematological changes in dermatitis herpetiformis. Lancet. 1967;2:29-33.

12. Handler MZ, Chacon AH, Shiman MI, Schachner LA. Application of dapsone $5 \%$ gel in a patient with dermatitis herpetiformis. J Dermatol. 2012;31:132-3.

13. Herrero-González JE. [Clinical guidelines for the diagnosis and treatment of dermatitis herpetiformis]. Actas Dermosifiliogr. 2010;101:820-6.

14. Hervonen K, Vornanen M, Kautiainen H, Collin P, Reunala T. Lymphoma in patients with dermatitis herpetiformis and their first-degree relatives. Brit $\mathbf{J}$ Dermatol. 2005; 152:82-6.

15. Kàrpàti S. Dermatitis herpetiformis. Clin Dermatol. 2012;30:56-9.

16. Kotze LMS. Celiac disease in Brazilian patients: associations, complications and causes of death. Forty-years of clinical experience. Arq Gastroenterol. 2009;46:261-9.

17. Kotze LMS, Brambila-Rodrigues AP, Kotze LR, Nisihara RM. A Brazilian experience of the self transglutaminase-based test for celiac disease finding and diet monitoring. World J Gastroenterol. 2009;15:4423-8.

18. Kotze LMS, Dalla Vecchia LA, Nisihara NM. Alta prevalência de dermatite herpetiforme em homens com doença celíaca. GED. 2012;31(Suppl 1):28-479.

19. Kotze LMS, Nisihara RM, Kotze LR, Utiyama SRR. Celiac disease and dermatitis herpetiformis in Brazilian twins: a long-term follow-up and screening of their relatives. J Pediatr Endocrinol Metab. 2012;26:71-5.
20. Kumar V, Jarzabek-Chorzelska M, Sulej J, Rajadhyaksha M, Jablonska S. Tissue transglutaminase and endomysial antibodies-diagnostic markers of gluten sensitive enteropathy in dermatitis herpetiformis . Clin Immunol. 2001;98:378-82.

21. Marakli SS, Uzun S, Ozbek S, Tuncer I. Dermatitis herpetiformis in a patien receiving infliximab for ankylosing spondylitis. Eur J Dermatol. 2008;18:88-9.

22. Marks J, Shuster S, Watson AJ. Small-bowel changes in dermatitis herpetiformis. Lancet. 1966;2:1280-2.

23. Oxentenko AS, Murray JA. Celiac disease and dermatitis herpetiformis: the spectrum of gluten-sensitivity enteropathy. Int J Dermatol. 2003; 42:585-7.

24. Rhodes LE, Tingle MD, Park BK, Chu P, Verbov JL, Friedmann PS. Cimetidine improves the therapeutic/toxic ratio of dapsone in patients on chronic dapsone therapy. Br J Dermatol.1995;132:237-62.

25. Rottmann LH. Details of the gluten-free diet for the patients with dermatitis herpetiformis. Clin Dermatol. 1991;9:404-14.

26. Sárdy M, Kárpáti S, Merk1 B, Paulsson M, Smyth N. Epidermal thansglutaminase(TGase 3) is the autoantigen of dermatitis herpetiformis. J Experim Med. 2002;195:747-57.

27. Schmidt E. [Optimizing therapy in patients with severe autoimmune blistering skin diseases]. Hautarzt. 2009;60:633-40.

28. Sener O, Doganci L, Safali M, Besirbellioglu B, Bulucu F, Pahsa A. Severe dapsone hypersentivity syndrome. J Invest Allerg Clin Immunol. 2006;16:268-70.

29. Sugai E, Smecuol E, Niveloni S, Vazquez H, Label M, Mazure R, Czech A, Kogan Z, Mauriño E, Bai JC. Celiac disease serology in dermatitis herpetiformis. Which is the best option for detecting gluten sensitivity? Acta Gastroenterol Latinoam. 2006;36:197-201.

30. The First Consensus Conference on Gluten Sensitivity, London; 2011.

31. Turchin I, Barankin B. Dermatitis herpetiformis and gluten-free diet. Dermatol Online J. 2005;11:6.

32. Van der Meer JB. Granular deposits of immunoglobulins in the skin of patients with dermatitis herpetiformis. An immunofluorescent study. Br J Dermatol. 1969;81:493-503

33. Volta U, Molinaro N, De Franchis R, Forzenigo L, Landoni M, Fratangelo D, Bianchi FB. Correlation between IgA antiendomysial antibodies and subtotal villous atrophy in dermatitis herpetiformis. J Clin Gastroenterol. 1992;14:298-301.

34. Warren SJP Cockerell CJ Characterization of a subgroup of patients with dermatitis herpetiformis with non-classical histologic features. Am J Dermatopathol 2002;24:305-8

35. Willsteed E, Lee M, Wong LC, Cooper A. Sulfasalazine and dermatitis herpetiformis. Australas J Dermatol. 2005;46:101-3.

36. Zone JJ. Skin manifestations of celiac disease. Gastroenterology. 2005;128:S87-S91.

37. Zone JJ, Meyer LJ, Petersen MJ. Deposition of granular IgA relative to clinical lesions in dermatitis herpetiformis. Arch Dermatol. 1996;132:912-8.

Received 24/5/2013 Accepted 12/7/2013 